\title{
OS LIMITES DE POLÍTICAS PÚBLICAS VOLTADAS PARA AGRICULTURA FAMILIAR EM PROMOVER ORGANIZAÇÃO SOCIAL: $O$ CASO DO ASSENTAMENTO 23 DE MAIO
}

\author{
André de Camargo Macedo ${ }^{1}$ \\ Bruna Carolina Meira \\ Edmilson Carlos de Almeida Lopes Junior ${ }^{3}$ \\ João Paulo Agápto ${ }^{4}$ \\ Ricardo Serra Borsatto ${ }^{5}$
}

\section{RESUMO}

O presente trabalho analisa os limites do Programa de Aquisição de Alimentos (PAA) e Programa Nacional de Alimentação Escolar (PNAE) em promover a organização social de agricultores familiares a partir do estudo de caso do assentamento 23 de Maio, localizado na região sudoeste do estado de São Paulo. Os resultados ora apresentados se basearam nas respostas atribuídas a dois questionários aplicados respectivamente aos assentados e ao gestor da associação existente no assentamento. Os resultados evidenciaram uma baixa participação dos agricultores nos processos administrativos e decisórios da associação, bem como que a associação tem atuado quase que exclusivamente como intermediária para a inserção da produção dos associados em mercados institucionais. A pesquisa também permitiu compreender pontos considerados negativos pelos agricultores em relação a sua participação em ambos os programas. Conclui-se que para o PAA e o PNAE promoverem a organização social de agricultores familiares assentados e assim serem mais eficientes no apoio à agricultura familiar, se faz necessária sua articulação com outras políticas públicas voltadas para este público.

Palavras-chave: agricultura familiar, coesão social, políticas públicas, segurança alimentar, sistemas agroalimentares localizados.

\footnotetext{
${ }^{1}$ Graduando em Engenharia Agronômica (UFSCar). Bolsista PIBIC/CNPq. E-mail: andre_macedo11@hotmail.com.

${ }^{2}$ Tecnóloga em Agronegócios (FATEC-Itapetininga). Especialista em Educação do Campo em Agroecologia na Agricultura Familiar e Camponesa (Unicamp). Graduanda em Engenharia Agronômica. (UFSCar). E-mail: brunac75@hotmail.com.

${ }^{3}$ Graduando em Engenharia Agronômica(UFSCar). Bolsista PIBIC/CNPq. E-mail: ecalopesjr@gmail.com.

${ }^{4}$ Tecnólogo em Agronegócios. (FATEC-Itapetininga), Especialista em Ciências Políticas (UCAM). Técnico em Agropecuária (UFSCar). E-mail: jpagapto@ufscar.br.

${ }^{5}$ Engenheiro Agrônomo (ESALQ/USP). Doutor em Planejamento e Desenvolvimento Rural Sustentável (Unicamp). Professor Adjunto na Universidade Federal de São Carlos (UFSCar). E-mail: ricardo.borsatto@ufscar.br.
} 


\title{
THE LIMITS OF PUBLIC POLICIES FOR FAMILY FARMING IN PROMOTING SOCIAL ORGANIZATION: THE CASE OF THE SETTLEMENT 23 DE MAIO
}

\begin{abstract}
This paper analyzes the limits of the Food Acquisition Program (PAA) and the National School Meal Program (PNAE) in promoting the social organization of family farmers, through the case study of the settlement "23 de Maio" in São Paulo state. Therefore, we developed and implemented two questionnaires, directed respectively to the settlers and the manager of the existing association in the settlement. The results showed a low participation of farmers in administrative and decision-making processes of the association, and the association has dedicated only to act as an intermediary for the insertion of the family farmers in an institutional markets. The research also allowed to understand points considered negative by farmers in respect of their participation in both programs. It was concluded that for the PAA and PNAE to promote the social organization of settled family farmers and thus be more efficient in supporting family farming, it is necessary to articulate with other public policies directed to this public.
\end{abstract}

Keywords: family farming, food security, localized agrifood systems, public policies, social cohesion.

\section{INTRODUÇÃO}

Motivados pela percepção dos limites que as políticas públicas de viés neoliberal voltadas para a agricultura têm em combater a pobreza e a fome, especialmente em países em desenvolvimento, desde meados da década de 1990 os debates sobre soberania e segurança alimentar vêm ganhando força ao redor do mundo (MOSELEY et al., 2010; ALTIERI; TOLEDO, 2011). Esses debates advogam a necessidade da reestruturação do sistema agroalimentar dominante, baseado em grandes e longas cadeias agroindustriais, sendo enfatizada a necessidade da elaboração e implementação de políticas públicas que estabeleçam apoios institucionais, de infraestrutura e legais, bem como proteção, para a emergência e consolidação de sistemas agroalimentares mais localizados (ALTIERI; NICHOLLS, 2008; WITTMAN, 2009; CONTI et al., 2015).

Os estudos de sistemas agroalimentares surgiram num contexto de agravamento das crises presentes nas sociedades rurais, assim como da ampliação dos problemas ambientais e alimentares ocasionados pelos sistemas produtivos baseados em processos de larga escala e longas cadeias. Essa abordagem tem como anseio a análise dos processos de produção, distribuição e consumo de alimentos, colocando em evidência o papel dos agricultores e minimiza a centralidade do papel do consumidor dentro dos sistemas, permitindo que a perspectiva territorial ganhe importância (SOLER, 2009).

Especificamente no Brasil, após as eleições presidenciais de 2002 e da posse do presidente Luiz Inácio Lula da Silva, abriram-se espaços na seara pública para a institucionalização de muitas ideias e reivindicações relacionadas ao tema da segurança alimentar e nutricional (SAN) (GRISA; SCHNEIDER, 2014). Como apontou Belik (2003), muitas das ações que buscam promover a SAN passam pelo fortalecimento de sistemas agroalimentares localizados, na busca de aproximar os produtores e consumidores de alimentos. Assim, a SAN passa a ser considerada na 
formulação de diferentes políticas públicas, sempre atrelada a percepção da importância de se valorizar a agricultura familiar na construção de sistemas agroalimentares mais equitativos e localizados.

Nesse contexto, os mercados institucionais podem ser utilizados como uma forma de intervenção pública para a construção de mercados mais "socialmente eficientes", por facilitar as relações comerciais ente os agentes com o intuito de promover a SAN e outras demandas de bem-estar social (BECKER; ANJOS, 2015).

Fornazier (2014) aponta que o acesso aos mercados pode ser uma oportunidade de incentivar a produção na agricultura familiar, visto que nem sempre os agricultores conseguem atender as condições para acessar os grandes mercados e a demanda local pode ser pequena. Assim, surgem propostas de utilizar a demanda dos equipamentos públicos para adquirir alimentos dos agricultores, servindo como instrumentos de inclusão produtiva da agricultura familiar. Ademais, os mercados institucionais podem atuar em determinantes estruturais da SAN, por meio da redução da volatilidade de preços e manutenção de cadeias agroalimentares mais localizadas.

O Programa de Aquisição de Alimentos da Agricultura Familiar (PAA) e o Programa Nacional de Alimentação Escolar (PNAE - Lei no 11.947/2009) emergem neste contexto, voltados a incentivar "novos" sistemas agroalimentares mais localizados, com protagonismo da agricultura familiar, que promovam a SAN de populações em risco de insegurança alimentar.

Não desmerecendo os pontos positivos que esses programas possuem, conforme já apontado em uma grande quantidade de trabalhos acadêmicos publicados, o artigo ora apresentado busca oferecer uma reflexão sobre os limites que estes programas possuem em promover, por si só, o desenvolvimento rural de comunidades de agricultores familiares.

Especificamente, neste trabalho, foi realizado um estudo de caso da Associação dos Amigos Produtores Rurais de Itapetininga (AAPRI), formada por agricultores do Assentamento 23 de Maio, localizado no município de Itapetininga no estado de São Paulo.

Buscou-se nessa pesquisa compreender o papel exercido pela associação no assentamento, verificando se que a mesma tem atuado como um agente de desenvolvimento local, superando o papel de mero intermediário nos processos de comercialização da produção via mercados institucionais.

O artigo começa apresentando um breve panorama desses programas (PAA e PNAE) voltados à promoção de mercados institucionais para a agricultura familiar. Seguido da descrição da abordagem metodológica adotada e dos resultados encontrados no decorrer da pesquisa. Por fim, conclui-se analisando os limites que estes programas apresentam em promover processos sustentáveis de desenvolvimento rural, mais especificamente em termos da construção/manutenção/fomento de sistemas agroalimentares mais localizados.

\section{REVISÃO DA LITERATURA}

\subsection{PROGRAMA DE AQUISIÇÃO DE ALIMENTOS (PAA)}

O PAA foi instituído em 2003 no contexto do Programa Fome Zero, sua origem remete a dois importantes debates ocorridos durante a década de 1990 no Brasil. O primeiro tinha como questões centrais o combate à fome e a garantia da segurança alimentar e nutricional da população brasileira. $O$ segundo debate era direcionado ao reconhecimento da importância da agricultura familiar como categoria social pelas políticas governamentais (GRISA et al., 2011; ROCHA et al., 2013). 
Os recursos para o desenvolvimento do programa são provenientes do Ministério do Desenvolvimento Social e Combate à Fome (MDS) e do Ministério do Desenvolvimento Agrário (MDA). A Companhia Nacional de Abastecimento (Conab) juntamente com os Estados e prefeituras são os responsáveis pela operacionalização do programa junto aos agricultores familiares.

De maneira geral, o PAA foi implantado com o intuito de atender a agricultura familiar através da aquisição de parte de sua produção a preços praticados nos mercados locais, dispensando a necessidade de licitações. Os produtos adquiridos se destinam a doações para rede socioassistencial, assim como para formação de estoques, assegurando alimentação em quantidade, qualidade e regularidade às populações em situação de insegurança alimentar e nutricional.

Nesta lógica, a operacionalização do PAA demonstra claramente a atuação do Estado no sentido de promover a comercialização da produção proveniente de agricultores familiares. A singularidade do tema, segundo Feltraco (2010), está relacionada com a importância assumida pela agricultura familiar no contexto das políticas públicas, bem como componente essencial para o desenvolvimento rural.

Outra característica importante desse programa é a sua perspectiva territorial, visto que busca que a produção agrícola de um determinado território seja consumida dentro do mesmo, aproximando os agricultores de seus consumidores, fomentando sistemas agroalimentares localizados (DIAS et al., 2013; VINHA; SCHIAVINATTO, 2015).

Ademais, o PAA contém uma diversidade de objetivos, sendo que muitos deles encontram-se implícitos, como a promoção da circulação de dinheiro na economia local, a exploração mais racional do espaço rural, distribuição de renda e preservação da agrodiversidade do território (BECKER et al., 2009).

Como demonstram diferentes estudos, o PAA vem alcançando a cada ano diversos de seus objetivos, promovendo a geração de renda e a sustentação de preços para os agricultores familiares, aliadas à mitigação da insegurança alimentar e nutricional de populações urbanas e rurais, bem como diversificação da produção, a consolidação de cadeias curtas de comercialização e a manutenção das famílias no campo (BALSADI, 2004; ALMEIDA; FERRANTE, 2009; HESPANHOL, 2009; TRICHES; SCHNEIDER, 2010; entre outros).

\subsection{PROGRAMA NACIONAL DE ALIMENTAÇÃO ESCOLAR (PNAE)}

A criação de um Programa Nacional de Alimentação Escolar (PNAE) ocorreu ainda na década de 1950, com o intuito de prover alimentação e nutrição adequadas para crianças e jovens escolares. Mas, foi a partir de 2003 que se sucedeu, na alimentação escolar, uma série de mudanças no sentido de incorporá-la a uma nova política de SAN coordenada pelo Programa Fome Zero (TAKAGI, 2006).

Em 2009 foi sancionada a Lei 11.947/09 a qual prevê que os recursos direcionados ao PNAE devem destinar-se, ao menos em parte, à aquisição de alimentos produzidos pela agricultura familiar (BRASIL, 2009).

Schneider et al. (2010) afirmaram que a Lei 11.947/09 foi um marco nas políticas públicas relacionadas à SAN, pois determina às entidades executoras do PNAE a utilizar no mínimo $30 \%$ do valor remetido pelo Fundo Nacional de Desenvolvimento da Educação (FNDE) na aquisição de gêneros alimentícios da agricultura familiar local ou regional. Por sua vez, Siqueira et al. (2014) destacam o caráter inovador da lei no que diz respeito à dispensa do processo licitatório quando o fornecedor for caracterizado como agricultor familiar, além de equiparar os preços com os vigentes no mercado local e priorizar, sempre que possível, alimentos oriundos de produção orgânica e/ou agroecológica. 
Como o programa possui abrangência nacional, gera um mercado institucional expressivo para a agricultura familiar escoar a sua produção. Também favorece a melhoria da alimentação dos estudantes, pois incentiva o consumo de alimentos mais frescos e saudáveis.

As verbas provenientes do governo federal para a compra de alimentos a serem servidos na merenda escolar são repassadas pelo FNDE para os estados e municípios, sendo calculadas de acordo com o número de estudantes. Com a Lei $11.947 / 09$, os alimentos adquiridos da agricultura familiar podem ser comprados pelos municípios ou estados através de chamadas públicas, isentando a necessidade de licitação. Inicialmente, era previsto um limite máximo de $R \$ 9.000,00$ por Declaração de Aptidão ao Pronaf (DAP)/ano, esse valor foi alterado em 2012 , passando para o limite máximo de $R \$ 20.000,00$ por DAP/ano, aumentando o impacto socioeconômico desse programa para a agricultura familiar.

Além da garantia de um novo mercado para os alimentos da agricultura familiar, essa política, ao menos em teoria, fomenta uma maior organização social dos agricultores, uma vez que a comercialização se dá prioritariamente através de associações e cooperativas.

No entanto, estudos têm apontado diferentes entraves que vêm dificultando a operacionalização do programa. Como descrevem Procopio et al. (2015) em seu estudo sobre o município de Itapeva-SP, problemas com a realização das chamadas públicas, dificuldades para o cumprimento das entregas por parte dos agricultores, cardápios não condizentes com a época agrícola das culturas ou que demandem alimentos não produzidos na região, falta de organização social dos agricultores, baixa qualidade da produção e limitada articulação entre o poder público e as organizações dos agricultores têm prejudicado o PNAE na consecução de seus objetivos.

Outra dificuldade encontrada foi o baixo interesse por parte de agricultores locais de participarem do programa, devido a evidente dificuldade para a realização das chamadas públicas e/ou a burocracia enfrentada pelos agricultores familiares que desejem entregar seus produtos via o programa (ESQUERDO; BERGAMASCO, 2014).

Estes entraves corroboram os dados sistematizados pelo estudo conduzido por Villar et al. (2013) que demonstrou que dos 613 municípios paulistas estudados, em aproximadamente $50 \%$ das prefeituras já havia sido realizada a compra de alimentos da agricultura familiar pelo menos uma vez. Em contrapartida, nos outros $50 \%$ não haviam sido realizadas todas as etapas para concretização do programa.

\section{METODOLOGIA}

\section{1.ÁREA DE ESTUDO}

Situado no distrito de Tupy, pertencente ao Município de Itapetininga, região sudoeste do Estado de São Paulo, o Assentamento 23 de Maio contempla uma área de 515 hectares que foi dividida em 46 lotes, cedida para o uso de 46 famílias. Tendo a sua imissão de posse datada em 8 de novembro de 2008.

Antes da constituição do assentamento, a área era ocupada por uma fazenda de gado de corte, intitulada Fazenda Eldorado, pertencente ao grupo Fazendas Reunidas Boi Gordo S/A, que devido a um colapso financeiro, acumulou dívidas com o governo e investidores. A fazenda foi adquirida da massa falida do grupo pelo Instituto Nacional de Colonização e Reforma Agrária e destinada para fins de reforma agrária (CAMARGO et al., 2013). 
Para coordenar e incentivar a produção agrícola no local, os assentados criaram uma associação, a Associação dos Amigos Produtores Rurais de Itapetininga (AAPRI), com a finalidade de melhor adequar a produção e prestar orientação aos seus associados quanto à participação em programas governamentais. A princípio, participavam da associação apenas 14 famílias. Atualmente, todas as 46 famílias de assentados são associadas à AAPRI.

Tendo como base o site da Transparência Pública do PAA, verificou-se que no último contrato relacionado ao PAA firmado pela AAPRI, datado de 2014 , participaram 38 associados, o que corresponde a aproximadamente $80 \%$ do total de famílias assentadas. Já em relação à participação no PNAE, segundo informações fornecidas pelo gestor da AAPRI, 28 famílias entregavam, no momento da pesquisa, alimentos para este programa, aproximadamente $60 \%$ do total dos associados.

Após identificar o número de famílias existentes no assentamento e o respectivo número de participantes dos programas no momento da execução dessa pesquisa, deu-se início ao trabalho de coleta de dados a campo.

Em relação ao número de entrevistados, o intuito era entrevistar o universo de agricultores participantes do PNAE (28), pois se considera que normalmente os agricultores que fornecem para o PNAE, atendem concomitantemente o PAA.

A aplicação dos questionários ocorreu no mês de fevereiro de 2016, sendo que ao final foram entrevistados 26 agricultores, além do presidente de AAPRI. Nota-se que o número de agricultores entrevistados (26) ficou aquém do desejado, este fato foi determinado por fatores externos à pesquisa, tais como a dificuldade de encontrar os agricultores em suas residências no momento da aplicação dos questionários e pelas limitações de deslocamento dentro do assentamento devido ao grande volume de chuvas à época da pesquisa.

Do total de 26 questionários aplicados aos agricultores, quatro foram desconsiderados devido à falta de consistência dos dados apresentados (preenchimento equivocado por parte dos entrevistadores e informações sem sentido). Assim, foram considerados na análise empreendida 22 questionários, sendo que dos entrevistados, todos os agricultores já haviam participado do PAA e 19 deles do PNAE.

\subsection{INSTRUMENTOS DE INVESTIGAÇÃO PARA LEVANTAMENTO DE DADOS E INFORMAÇÕES}

Para a coleta de dados primários de interesse da pesquisa, foram elaborados e testados dois questionários, com perguntas abertas e fechadas, para serem aplicados respectivamente aos agricultores participantes dos programas e a ao gestor da AAPRI. Cada questionário era estruturado em quatro blocos distintos.

No primeiro bloco, as questões buscavam coletar informações sobre o acesso dos agricultores aos programas. O segundo bloco era composto por perguntas que visavam compreender a percepção dos agricultores em relação às atividades exercidas pela associação e, no caso do questionário direcionado ao gestor, a percepção deste em relação à participação dos agricultores na associação. O terceiro bloco continha questões que buscavam captar a opinião dos agricultores e do gestor sobre o PAA e o PNAE, buscando compreender as dificuldades encontradas para a participação nos programas e as possíveis melhorias no ponto de vista dos atores. As respostas às questões destes três blocos foram tabuladas e analisadas por meio de estatística descritiva.

Por fim, o quarto bloco firmou-se em questões que possibilitavam a compreensão da coesão social da relação entre a associação e os associados. Para esta análise foram utilizados indicadores elaborados a partir dos trabalhos de 
Almeida e Ferrante (2009), Almeida et al. (2010) e Paulillo et al. (2009), que visaram avaliar as características dos membros da rede e os atributos de suas relações, conforme apresentado no quadro 1.

Quadro 1 - Indicadores de coesão social utilizados na pesquisa

\begin{tabular}{|ll|l|}
\hline \multicolumn{2}{|c|}{ Indicadores } \\
\hline \multicolumn{2}{|c|}{ Características dos membros } & \multicolumn{1}{c|}{ Atributos das relações } \\
\hline a) & Agilidade & g) Comunicação \\
b) & Reputação & h) Regras e usos \\
c) & Esforço para manutenção dos atores & i) Centralidade \\
d) & Esforço para novas opções e ganhos & j) Controle \\
e) & Cooperação & k) Frequência \\
f) & Reciprocidade & l) Confiança \\
\hline
\end{tabular}

Fonte: Elaborado pelos autores a partir de Almeida et al. (2009; 2010) e Paulillo et al. (2009).

Para cada indicador, foi elaborada uma questão contida nos questionários aplicados. A elaboração das questões e suas opções de resposta foram baseadas na escala Likert, isto é ao responderem os questionários, os perguntados especificavam seu nível de concordância com a questão apresentada. .

Deste modo, cada questão permitia cinco opções de respostas, que variavam de total discordância a total concordância. As respostas às questões foram analisadas em relação às suas frequências ao grau de concordância com a afirmação. Assim, em função do número de respondentes que "concordavam" ou "concordavam muito" com a afirmação, foram atribuídas às avaliações de cada indicador conforme apresentado no quadro 2.

Quadro 2- Definição do grau de coesão social em função das respostas atribuídas pelos entrevistados.

\begin{tabular}{|c|c|}
\hline $\begin{array}{c}\text { Porcentagem de respostas } \\
\text { positivas }\end{array}$ & Grau de coesão \\
\hline $0-25 \%$ & Fraco \\
$25-50 \%$ & Moderado \\
$50-75 \%$ & Forte \\
$75-100 \%$ & Muito Forte \\
\hline
\end{tabular}

Fonte: Elaborado pelos autores.

\section{RESULTADOS E DISCUSSÕES}

\subsection{LIMITES DO PAA E DO PNAE}

Apesar de todos os entrevistados considerarem que o PAA e o PNAE são importantes programas de incentivo à produção e geração de renda, por intermédio da metodologia adotada pôde-se identificar as dificuldades e limitações para o bom desenvolvimento dos programas em âmbito local.

Dentre as limitações mencionadas ao longo das entrevistas com os agricultores, foi relatado que o preço pago aos produtos é um dos principais problemas existentes em ambos os programas. Dentre os 22 entrevistados, $32 \%$ informaram que os preços baixos pagos pelos produtos destinados a tais mercados institucionais acabam por desestimular um maior interesse pelos programas. Situação similar foi encontrada por Scheuer et al. (2016) em estudo realizado no município de São José dos Quatro Marcos - MT, no qual de um universo de 46 agricultores entrevistados, $24,36 \%$ apontaram que o PAA deveria pagar mais pelos produtos adquiridos. 
Atrasos nos pagamentos é outro fator que interfere negativamente na avaliação dos programas. Dos entrevistados, 27,2\% apontaram enfrentar problemas com atrasos nos pagamentos dos programas, o que segundo eles acaba por desestimular a permanência no PAA e no PNAE. Resultados similares foram encontrados em outras análises sobre PAA (GOMES; BASTOS, 2007; SCHEUER et al., 2016), sendo este um fator desalentador e frustrante para os agricultores e associações/cooperativas, gerando até mesmo um descrédito em relação à política pública.

Outro entrave destacado pelos agricultores diz respeito à existência de problemas logísticos. Dos entrevistados, $22,7 \%$ alegaram enfrentar problemas com esta variável, a qual se relaciona a falta de planejamento tanto produtivo quanto da comercialização propriamente dita. A percepção de que as políticas públicas têm problemas relacionados à logística foi também mencionado em outros trabalhos de escopo similar(TRICHES et al., 2014; SCHEUER et al., 2016).

Os agricultores entrevistados também apontaram que exigências relacionadas à qualidade dos produtos são um dos problemas vivenciados, principalmente para acessar o PNAE, sendo relatado que em alguns casos houve a devolução dos alimentos entregues.

Destaca-se no caso aqui estudado, que o acesso ao PAA e PNAE não foi suficiente para que se consolidassem sistemas agroalimentares localizados com maior grau de complexidade, sendo que os agricultores entrevistados ainda possuem elevada dependência destes programas para escoar a sua produção. Isso ocorre apesar do assentamento estar próximo de grandes centros consumidores e com fácil acesso logístico.

\subsection{ANÁLISES DAS RELAÇÕES FIRMADAS ENTRE OS ATORES PARTICIPANTES DOS PROGRAMAS}

A pesquisa empreendida também permitiu compreender as relações estabelecidas entre os assentados e a associação, bem como o papel desta como órgão representativo dos interesses de seus associados. Em relação à participação dos agricultores nos programas, identificou-se que dos 22 agricultores entrevistados, $63,6 \%$ (14) informaram que sua participação na associação se limitava à entrega dos produtos destinados ao PAA e PNAE, 27,3\% (6) apontaram além de entregarem seus produtos para a comercialização, também participam de reuniões e debates promovidos pela associação, enquanto $9,1 \%$ (2) dos entrevistados disseram ter auxiliado na elaboração de projetos e assumirem cargos administrativos na AAPRI.

Por sua vez, quando questionado sobre a participação dos agricultores na associação, o gestor apontou que este é um dos problemas a serem trabalhados, pois segundo ele os agricultores pouco participam dos processos políticos e decisórios.

A pesquisa identificou que as reuniões da AAPRI ocorrem de maneira esporádica e a utilização de ferramentas de comunicação é precária, restrita, na maior parte dos casos, ao método informal "boca a boca". Ainda, segundo os relatos, a associação se incumbe somente de assuntos relacionados à comercialização via mercados institucionais, não trabalhando outros temas de interesse da comunidade. Assim os associados não estavam motivados a participarem mais ativamente das reuniões.

Estas informações desvelam que a AAPRI representa de forma muito limitada o interesse de seus associados, sendo considerada por significativa parte de seus associados como um mero organismo intermediador para comercializar parte de sua produção. 
Ao avaliar o grau de importância da AAPRI, 50\% dos entrevistados declararam a associação como sendo ótima e importante, no entanto os outros $50 \%$ atestaram a existência de problemas e dificuldades, avaliando negativamente a organização.

Quando arguidos sobre os problemas e dificuldades vivenciados em seu relacionamento com a associação, 18\% (4)dos agricultores apontaram a existência de problemas vinculados à frequência de entrega dos produtos, concomitantemente ao baixo volume de produtos a serem comercializados por produtor.

Nas figuras 1 e 2 é possível observar a coesão social da relação associação $\mathrm{x}$ associados a partir dos indicadores selecionados por esta pesquisa, em cada um dos programas estudados.

Figura 1 - Avaliação da coesão social no PAA - Relação entre associação e associados no contexto do PAA

\begin{tabular}{|c|c|c|c|c|}
\hline \multicolumn{4}{|c|}{$\mathrm{CM}=++, \mathrm{RU}=+++, \mathrm{CL}=++, \mathrm{CT}=++$, } & \\
\hline $\mathrm{AG}=$ & $\mathrm{RP}=$ & $A G-$ & PP- & \\
\hline $\begin{array}{l}\text { EF.M } \\
=++\end{array}$ & $\begin{array}{c}\mathrm{RC}= \\
++\end{array}$ & & $\mathrm{RC}=+$ & EF.M=++ \\
\hline $\begin{array}{l}\text { EF.G } \\
=\end{array}$ & $\begin{array}{c}\mathrm{CP}= \\
+\end{array}$ & $\mathrm{EF} . \mathrm{G}=$ & $\mathrm{CP}=+$ & \\
\hline
\end{tabular}

Fonte: Dados da pesquisa.

Legenda: $\mathrm{AG}=$ Agilidade; $\mathrm{RP}=$ Reputação; $\mathrm{EF} . \mathrm{M}=$ Esforço para manutenção de atores; $\mathrm{RC}=\mathrm{Reciprocidade}$ $E F . G=$ Esforço para novos ganhos; $C P=$ Cooperação; $C M=$ Comunicação; $R U=$ Regras e usos; $C L=$ Centralidade; $\mathrm{CT}=$ Controle; $\mathrm{FQ}=$ Frequência; $\mathrm{CF}=$ Confiança.

Direcionadores: Forte: +++; Moderado: ++; Fraco: +; Muito Fraco: -.

Na figura 1 é possível analisar que o indicador Cooperação é o que possui menor avaliação segundo opinião dos agricultores. Para eles, a AAPRI, além de pouco ter cooperado na inserção dos agricultores em outros meios de comercialização, tem atuado de forma bastante limitada em atividades de interesse coletivo, tais como: organização de eventos, cursos e palestras aos agricultores, auxílio no atendimento às necessidades da comunidade, processamento da produção e viabilização/mediação na compra de insumos.

Em alusão aos indicadores que apresentaram resultados moderados a partir da opinião dos agricultores, citam-se os indicadores de Agilidade, Reputação, Esforços para Novos Ganhos, Esforços para Manutenção dos Atores.

$O$ indicador Agilidade demonstra que apesar da morosidade em diversos processos, tais como pagamentos e informações, a associação tem se empenhado no atendimento das necessidades e reivindicações dos agricultores. Em referência à Reputação, observou-se que a AAPRI tem cumprido de maneira moderada com o que é prometido aos associados. Quanto ao indicador Esforços para Manutenção dos Atores e Reciprocidade, identificou-se que a associação pouco tem se esforçado para atender/compreender as necessidades e demandas dos agricultores em relação ao PAA, assim como pouco tem buscado a incorporação de novos 
associados ao programa, conforme resultado apresentado pelo indicador Esforços para Novos Ganhos.

Por outro lado, a percepção do gestor em relação aos associados indica uma avaliação mais positiva. De acordo com o gestor da AAPRI, os agricultores foram bem avaliados nos indicadores Agilidade, Reputação e Reciprocidade, o que evidência que os associados estão comprometidos em constituir uma rede que atenda as demandas do PAA.

Ao que se refere à interpretação dos indicadores Cooperação e Esforços para Manutenção dos Atores e Esforço para Novos Ganhos, os resultados obtidos foram semelhantes aos apresentados na avaliação efetuada pelos agricultores acerca da associação.

No tocante aos indicadores que caracterizam a relação dos atores, observase que o indicador Regras e Usos é plenamente cumprido por ambos os atores. No que diz a respeito ao indicador Comunicação, tanto a associação como os agricultores apontam que o fluxo de informações pode ser ainda aprimorado.

Em relação aos indicadores Centralidade, Controle, Frequência e Confiança o gestor expressou que os agricultores atendem de forma bastante satisfatória, em contra partida os agricultores consideraram que existe espaço para melhorar a atuação da associação nessas dimensões.

A figura 2 apresenta os indicadores de coesão social da relação associação $x$ associados da AAPPRI no contexto do PNAE.

Figura 2 - Avaliação da coesão social no PNAE - Relação entre associação e associados no contexto do PNAE

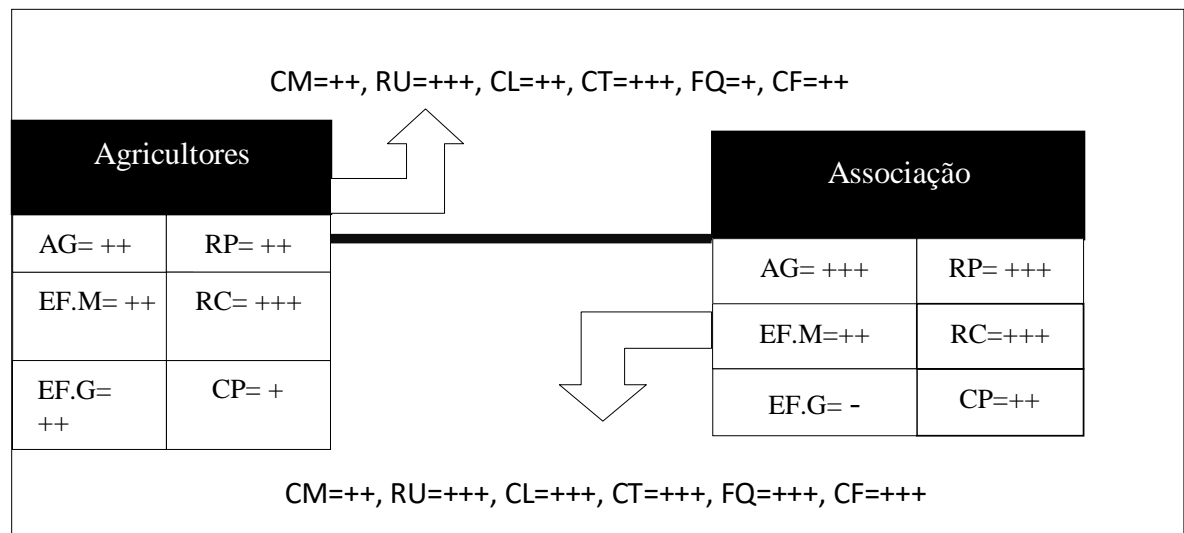

Fonte: Dados da pesquisa.

Legenda: $A G=$ Agilidade; $R P=$ Reputação; $E F . M=$ Esforço para manutenção de atores; $R C=$ Reciprocidade;

$\mathrm{EF} . \mathrm{G}=$ Esforço para novos ganhos; $\mathrm{CP}=$ Cooperação; $\mathrm{CM}=$ Comunicação; $\mathrm{RU}=$ Regras e usos; $\mathrm{CL}=$

Centralidade; $\mathrm{CT}=$ Controle; $\mathrm{FQ}=$ Frequência; $\mathrm{CF}=$ Confiança.

Direcionadores: Forte: +++; Moderado: ++; Fraco: +; Muito Fraco: -.

As avaliações das relações firmadas no âmbito do PNAE se diferenciam das realizadas no âmbito do PAA em alguns pontos.

$O$ indicador Reciprocidade, elaborado a partir das opiniões dos agricultores, foi bem avaliado, pois os agricultores expressaram que a associação se esforça em compreender as necessidades e demandas dos associados. $\mathrm{O}$ mesmo aconteceu com o indicador Controle, visto que os agricultores apontaram ter um maior domínio sobre a organização da produção destinada ao PNAE e sobre as regras do programa. 
Por outro lado, o indicador Frequência apresentou uma avaliação fraca por parte dos agricultores, justificada pela maior demora da firmação dos contratos em relação aos convênios estabelecidos no PAA.

$\mathrm{Na}$ observação do indicador Esforços para Novos Ganhos, conforme parecer do gestor da Associação, este foi avaliado como muito fraco. Esse resultado expressa a dificuldade dos agricultores de inovarem na busca de Novos Ganhos, como por exemplo, produzirem de forma agroecológica/orgânica ou "agroindustrializarem" parte de sua produção.

Os demais indicadores avaliados no PNAE expressaram resultados semelhantes ao PAA, tendo por justificativa as mesmas discussões apresentadas anteriormente.

\section{CONCLUSÃO}

Partindo das análises efetuadas com as informações levantadas no decorrer desta pesquisa foi possível verificar que o PAA e o PNAE são importantes programas de fomento à inclusão produtiva de beneficiários de programas de reforma agrária.

Sabendo-se que ambos os programas possuem como intuito a promoção da segurança alimentar e nutricional, na rede estabelecida a partir da AAPRI esse objetivo vem sendo atingido de forma satisfatória junto aos agricultores. Os resultados desta pesquisa corroboram dados de outro trabalho anteriormente realizado no assentamento 23 de Maio, o qual demonstrou que, a partir do acesso a tais programas, houve a diversificação da produção, consumo dos produtos locais e consequentemente uma maior autonomia dos agricultores em relação ao mercado externo para aquisição de gêneros alimentícios (CAMARGO et al., 2013).

Por outro lado, apesar da inconteste relevância destes programas, os dados sistematizados por este estudo de caso apontam que somente estes programas têm sido insuficientes para promover a construção de sistemas agroalimentares com maior grau de complexidade, visto que as entrevistas evidenciaram que os programas são o principal (muitas vezes o único) meio de escoamento da produção para grande parte dos agricultores. A AAPRI, atualmente, tem atuado quase que exclusivamente como um intermediário para o acesso a mercados institucionais, não apoiando 0 acesso a outros mercados, nem promovendo processos de industrialização da produção com vistas a agregar valor.

A pesquisa de campo evidenciou que os programas ora estudados incentivaram a constituição da AAPPRI, que além de intermediar a comercialização para mercados institucionais, foi um importante ator no passado para consecução de benfeitorias de uso coletivo (como barracão e climatizador de bananas) e na implementação de projetos voltados à recuperação de áreas de preservação permanente. Mas também desvelou que os agricultores pouco têm participado dos processos decisórios da associação, bem como que a AAPRI não tem atuado no planejamento da produção, nem buscado compreender outras demandas dos seus associados para além da comercialização via mercados institucionais.

A análise da relação entre os atores (agricultores e associação) demonstrou que a associação tem falhado nos processos de comunicação com seus associados, visto que os agricultores pouco têm se apropriado dos objetivos e processos de funcionamento dos programas. Fato que propicia desconfianças e desinteresse por parte dos agricultores, fazendo com que estes atores pouco contribuam com os processos políticos e decisórios acerca do PAA e PNAE.

Os indicadores de coesão social demonstraram que ainda existem pontos que devem ser aprimorados com o objetivo de melhorar a efetividade dos programas 
em nível local. Destaca-se que os agricultores percebem que o trabalho da AAPRI tem sido insuficiente para atender às suas demandas, isto ficou evidente nos resultados dos indicadores de Cooperação, Reputação, Reciprocidade, Esforço para Novos Ganhos e Esforço para Manutenção de Atores. Por outro lado o gestor da AAPRI reclama da baixa participação dos associados e de que estes não têm interesse de apoiar à associação na busca de soluções para os seus problemas.

No que diz respeito às limitações do PAA e PNAE apontados pelos agricultores, destacam-se o preço baixo pago pelos produtos, os atrasos no pagamento e problemas logísticos. Especificamente em relação ao PNAE destacamse também reclamações relacionadas à maior exigência na qualidade da produção.

Infere-se que para uma melhor efetividade dos programas, é fundamental que estes incentivem uma melhor organização social dos agricultores familiares. $O$ estudo de caso ora realizado demonstra que isto é muito difícil de ocorrer sem o apoio de outras ações como, por exemplo, o acesso aos serviços de Assistência Técnica e Extensão Rural (ATER).

Em suma a atuação da AAPRI limita-se, neste momento, a intermediar os processos de comercialização da produção do assentamento via mercados institucionais, ficando aquém de protagonizar a função de agente de desenvolvimento local, o que condiciona que o sistema agroalimentar constituído a partir do Assentamento 23 de Maio seja ainda dependente do PAA e PNAE para sua manutenção. Deste modo, reveses nestes programas provavelmente acarretarão na desestruturação da rede estabelecida.

\section{REFERÊNCIAS}

AGAPTO, J. P.; BORSATTO, R. S.; ESQUERDO, V. F. S. et al. Avaliação do Programa de Aquisição de Alimentos (PAA) em Campina do Monte Alegre, estado de São Paulo, a partir da percepção dos agricultores. Informações Econômicas, v. 42, n. 2, p. 13-21, mar./abr. 2012.

ALMEIDA, L. M. M. C.; FERRANTE, V. L. S. B.; PAULILLO L. F. Rede de segurança alimentar de forte coesão social, a partir do Programa de Aquisição de Alimentos (PAA) no município de Araraquara-SP. Organizações Rurais \& Agroindustriais, v.12, n.3, p.370-385, 2010.

ALMEIDA, L. M. M. C.; FERRANTE, V. L. S. B. Programas de segurança alimentar e agricultores familiares: a formação de rede de forte coesão social a partir do PAA no município de Araraquara-SP. In: 47 Congresso Nacional da Sociedade Brasileira de Economia, Administração e Sociologia Rural. Porto Alegre/RS. Anais..., 2009. v. 1. p. 123-143.

ALTIERI, M.; NICHOLLS, C. Scaling up agroecological approaches for food sovereignty in Latin America. Development, v. 51, n. 4, p. 472-480, 2008.

ALTIERI, M.; TOLEDO V.M., The Agroecological Revolution of Latin America: Rescuing Nature, Securing Food Sovereignty and Empowering Peasants. Journal of Peasant Studies, v. 38, n. 3, p. 587-612, 2011.

BACCARIN, J. G.; ALEIXO, S. E.; SILVA, D. B. P.; MENDONÇA, G. G. Alimentação escolar e assentamentos rurais: uma análise dos limites e das possibilidades da 
implantação do artigo 14 da Lei 11.947/2009 no estado de São Paulo. In: V Jornada de Estudos em Assentamentos Rurais. 2011. Campinas-SP, Anais..., Cd-rom.

BALSADI, O. V. Programa de aquisição de alimentos da agricultura familiar: os primeiros resultados obtidos em 2003. Informações Econômicas, São Paulo, v. 34, n. 5, p. 35-46, maio 2004.

BECKER, C.; ANJOS, F. S.; CALDAS, N. V. Políticas públicas estruturantes e

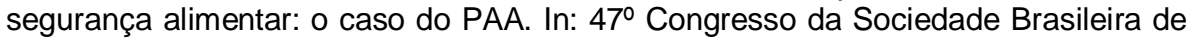
Economia, Administração e Sociologia Rural. Porto Alegre, Anais..., 2009.

BECKER, C.; ANJOS, F. S. São os mercados institucionais da agricultura familiar um instrumento para o desenvolvimento rural? Estudo de caso em municípios do sul do Brasil. Revista da Faculdade de Agronomia, v. 114, p.143-152. 2015.

BELIK, W. Perspectivas para segurança alimentar e nutricional no Brasil. Saúde e Sociedade. São Paulo, v. 12, n. 1, p. 12-20, jan./jun. 2003.

BRASIL. Lei 11.947 de 16 de junho de 2009. Dispõe sobre o atendimento da alimentação escolar e do Programa Dinheiro Direto na Escola aos alunos da educação básica; altera as Leis nos 10.880, de 9 de junho de 2004, 11.273, de 6 de fevereiro de 2006, 11.507, de 20 de julho de 2007; revoga dispositivos da Medida Provisória no 2.178-36, de 24 de agosto de 2001, e a Lei no 8.913, de 12 de julho de 1994; e dá outras providências. Disponível em: <http://www.planalto.gov.br/ccivil_03/_ato2007-2010/2009/lei/l11947.htm>. Acesso em: 30 abr. 2016.

CAMARGO, E. A. O. M.; GOMES, R. R. S.; MEIRA, B. C. et al. O Programa de Aquisição de Alimentos (PAA) como instrumento de fortalecimento de assentamentos rurais: o caso do Assentamento 23 de Maio, Itapetininga, Estado de São Paulo. Informações Econômicas, v. 43, p. 18-28, 2013.

CONTI, I. L.; BAZOTTI, A.; RADOMSKY, G. F. W. Agricultura Familiar e segurança alimentar e nutricional: um estudo sobre a relação produção-consumo nos municípios de Toledo (PR) e Contagem (MG). Extensão Rural, Santa Maria, v. 22, n. 1 1, jan./mar. 2015.20 Disponível <https://periodicos.ufsm.br/extensaorural/article/view/11935> Acesso em: 20 maio 2017.

DIAS, T. F.; NUNES, E. M.; TORRES, F. L. et al. O Programa de Aquisição de Alimentos da Agricultura Familiar (PAA) como estratégia de inserção socioeconômica: o caso do Território da Cidadania Sertão do Apodi (RN). G\&DR. v. 9, n. 3, p. 100-129, 2013.

ESQUERDO, V.F.S.; BERGAMASCO, S.M.P.P.; Análise sobre o acesso aos programas de políticas públicas da agricultura familiar nos municípios de Circuito das Frutas (SP). Rev. Econ. Sociol. Rural, Piracicaba-SP, v. 52, n. S1, 2014.

FELTRACO, S. L. Relatório contendo resultados de aplicação dos recursos do Programa de Aquisição de Alimentos - PAA, no quadriênio 2006/2009 em suas 
diversas modalidades, regiões, estados e beneficiários com a fonte de recursos do MDA. Maio, 2010.

FORNAZIER, A. Inserção de produtores rurais familiares de regiões com baixa dinâmica econômica para o mercado da alimentação escolar. 2014. 179 p. Tese (Doutorado em Desenvolvimento Econômico) - Instituto de Economia, Universidade Estadual de Campinas, Campinas, 2014.

FUSCALDI, K. C. Políticas de apoio à agricultura familiar: uma análise do Programa de Aquisição de Alimentos - PAA. Sociedade e desenvolvimento rural, v. 4, n. 1, jun. 2010.

GOMES, A.; BASTOS, F. Limites e possibilidades da inserção da agricultura familiar no PAA em Pernambuco. Sociedade e desenvolvimento rural. v.1, n.1, 2007.

GRISA, C.; SCHMITT, C. J.; MATTEI, L. F. et al. Contribuições do Programa de Aquisição de Alimentos à segurança alimentar e nutricional e à criação de mercados para a agricultura familiar. Agriculturas, v.8, n.3, set. 2011, p.34-41.

GRISA, C.; SCHNEIDER, S. Três gerações de políticas públicas para a agricultura familiar e formas de interação entre sociedade e estado no Brasil. Revista de Economia e Sociologia Rural, Brasília, v. 52, supl. 1, p. 125-146, 2014. Disponível em <http://dx.doi.org/10.1590/S0103-20032014000600007>. Acesso em: 23 maio de 2017.

GUANZIROLI, C.E. PRONAF dez anos depois: resultados e perspectivas para o desenvolvimento rural. Revista de Economia e Sociologia Rural, Brasília, v. 45, n. 2, jun. 2007.

HESPANHOL, R. A. M. Programa de Aquisição de Alimentos: limites e potencialidades de políticas de segurança alimentar para a agricultura familiar. Sociedade \& Natureza, Uberlândia/MG, v. 25, n. 3, p. 469-483, dez. 2013.

HESPANHOL, R.M. O programa de aquisição de alimentos (PAA) na região de Dracena (SP). In: Congresso SOBER, 47, 2009, Porto Alegre/RS, Anais... Brasília: SOBER, 2009.

MOSELEY, W. G.; CARNEY, J.; BECKER, L. Neoliberal policy, rural livelihoods, and urban food security in West Africa: a comparative study of The Gambia, Côte d'Ivoire, and Mali. Proceedings of the National Academy Science of USA, v. 107, n. 13, p. 5774-5779, 2010.

MOTA, D. M. et al. As catadoras de mangaba no Programa de Aquisição de Alimentos - PAA: um estudo de caso em Sergipe. Revista de Economia e Sociologia Rural, Brasília, v. 52, n. 3, p. 449-470, set. 2014.

PAULILLO, L. F. Entraves para políticas locais de segurança alimentar: uma análise comparativa da eficácia e aplicabilidade dos programas e redes de inclusão criadas em municípios paulistas. São Carlos (SP): UFSCar, 2006. Projeto de 
pesquisa apresentado ao Programa de Bolsa de Produtividade em Pesquisa do CNPq.

PAULILLO, L. F.; ALMEIDA, L. M.; SILVA, V. et al. Eficácia e coesão social do Projeto Viva Leite: uma avaliação da rede de segurança alimentar na região da Grande São Paulo. Rev. de Economia Agrícola, v. 56, n. 2, p. 61-76, 2009.

PAULILLO, L. F.; ALVES, F. Reestruturação agroindustrial- políticas públicas e segurança alimentar regional. São Carlos: EDUFCAR, 2002.

PROCOPIO, F. C.; OLIVEIRA, J. T. A.; BORSATTO, R. S.; As dificuldades para a participação de assentamentos rurais no Programa Nacional de Alimentação Escolar (PNAE): o caso de Itapeva-SP. Retratos de Assentamentos. Araraquara-SP, v.18, n.1, 2015.

ROCHA, J. H.; ANJOS, F. S. A sociologia econômica e os mercados protegidos: um arcabouço teórico e analítico para o Programa de Aquisição de Alimentos. Extensão Rural, Santa Maria, v. 20, n. 2, p. 30-61, mai./ago. 2013. Disponível em: <https://periodicos.ufsm.br/extensaorural/article/view/8325>. Acesso em: 20 maio 2017.

SCHEUER, J. M.; NEVES, S. M. A.; MOURA, A. P.; NEVES, R. J. Aspectos Socioeconômicos dos Agricultores Familiares da Associação dos Pequenos Produtores da Região do Alto Sant'ana, Mato Grosso. G\&DR, v. 12, n. 1, 2016.

SCHNEIDER, S.; CARVALHO, A.; GOMES, A.; SOUZA, M.; LUNARDI, R. Projeto de Pesquisa IPODE - "Sementes e Brotos" da transição: inovação poder e desenvolvimento em áreas rurais do Brasil. Desenvolvido pela Faculdade de Ciências Econômicas da Universidade Federal do Rio Grande do Sul, Porto Alegre, 2010.

SIQUEIRA, H. M.; LACERDA, M. G. F.; RODRIGUES, R. et al. Comercialização solidária da produção familiar de alimentos em Alegre - ES. Extensão Rural, Santa Maria, v.21, n.3, p.98-118, set./dez. 2013. Disponível em: <https://periodicos.ufsm.br/extensaorural/article/view/8336/pdf>. Acesso em: 20 maio 2017.

SOLER, M. M. El contexto socioeconómico de la agricultura ecológica: la evolución de los sistemas agroalimentarios. Master en Agroecología: un enfoque sustentable de la agricultura Ecológica. Universidad Internacional de Andalucía/Universidad de Córdoba, 2009.

TAKAGI, M. A implantação da política de segurança alimentar e nutricional no Brasil: seus limites e desafios. Tese (Doutorado em Economia) - Unicamp/ IE. Campinas, SP, 2006.

TRICHES, R. M.; GRISA, C. Entre mudanças e conservadorismos: uma análise dos Programas de Aquisição de Alimentos (PAA e PNAE) a partir da retórica da intransigência. In: Congresso da Sociedade Brasileira de Economia, Administração e Sociologia Rural, 52, 2014, Goiânia. Anais... Goiânia (GO): SOBER, 2014. 
TRICHES, R.M.; SCHNEIDER, S. Alimentação escolar e agricultura familiar: reconectando o consumo à produção. Saúde e Sociedade, São Paulo, v. 19, n. 4, 2010.

UZZI, B. Social structure and competition in interfirm networks. European Journal of Political Research, v. 22, p. 29-52, 1997.

VILLAR, B. S. et al. Situação dos municípios do estado de São Paulo com relação à compra direta de produtos da agricultura familiar para o Programa Nacional de Alimentação Escolar (PNAE). Revista Brasileira de Epidemiologia, São Paulo, v.16, n.1, p.223-226, mar. 2013.

VINHA, J.F.S.C.; SCHIAVINATTO, M. Soberania alimentar e territórios camponeses: uma análise do Programa de Aquisição de Alimentos (PAA). Revista NERA. v.18, n.26, p.183-203, 2015.

WITTMAN, H. Reworking the metabolic rift: la via campesina, agrarian citizenship, and food sovereignty. Journal of Peasant Studies, v. 36, n.4, p. 805-826, 2009. 